\title{
Morphology and epidemiological study of idiopathic scoliosis among primary school students in Chaozhou, China
}

\author{
Zemin Cai ${ }^{1}$, Ruibin $\mathrm{Wu}^{2}$, Shukai Zheng ${ }^{1}$, Zhaolong Qiu' ${ }^{1}$ and Kusheng $\mathrm{Wu}^{1 *}$ (B)
}

\begin{abstract}
Background: Idiopathic scoliosis (IS) affects patients' quality of life, yet there have been few reports of its morphology and epidemiological study in the southeast region of China. The aim of this study is to access the curve characteristics, prevalence, and factors associated with IS in Chaozhou city.

Methods: A cross-sectional study was performed in 2018, in which scoliosis screening was conducted among 5497 primary school students in Chaozhou city. Then, a case-control study based on the screening involving 2547 children was followed for the exploration of the associated factors. The questionnaires covering demographic characteristics, postural habits, cognition and self-sensation of scoliosis, and physical conditions were addressed for the investigation. ORs with $95 \% \mathrm{Cls}$ were calculated based on logistic regression analysis to evaluate the factors associated with scoliosis.

Results: The prevalence of IS among primary school students was 6.15\% in Chaozhou city, with 4.04\% for males and $8.71 \%$ for females. The average Cobb angle was $15^{\circ}$ (range 8 to $37^{\circ}$ ). Multiple logistic regression analysis suggested that female $(O R=2.45)$, BMI $(O R=0.67)$, having myopia $(O R=1.49)$, self-sensation of scoliosis with symptoms $(O R=5.52)$, insufficient sleep time $(O R=2.65,3.33)$, and less exercise time $(O R=7.09,7.29)$ were significantly associated with IS.

Conclusions: The prevalence of IS among primary school students in Chaozhou was at an average level, and it was significantly higher in females than in males. Lower body mass, having myopia, insufficient sleep time, and lower physical activity were associated with IS.
\end{abstract}

Keywords: Idiopathic scoliosis, Scoliosis screening, Prevalence, Associated factors

\section{Background}

Scoliosis is a transverse and rotated spine curvature that usually occurs in children or around puberty [1]. Clinically, patients frequently suffer from back pain symptoms. For severe patients, scoliosis can affect limb symmetry, appearance, and even affect the functions of the heart, lung, gastrointestinal or other internal organs, motor

\footnotetext{
* Correspondence: kswu@stu.edu.cn

'Department of Preventive Medicine, Shantou University Medical College, No.22, Xinling Rd, Shantou 515041, Guangdong Province, China Full list of author information is available at the end of the article
}

coordination ability, or activity ability [2, 3]. According to the pathogenesis, scoliosis can be sorted as idiopathic scoliosis (IS) and non-idiopathic scoliosis. The proportion of IS is $80 \%$ among scoliosis, mainly in adolescent girls [4].

IS screening among school children is vital for diagnosis and confirming progression of the curve. According to the previous researche $\mathrm{s}[5-8]$, the IS prevalence was mostly between $2 \%$ and $16 \%$. The prevalence of IS in females was about four times higher than that in males [9]. With a curve progression of $\leq 10^{\circ}$ studied, the

(c) The Author(s). 2021 Open Access This article is licensed under a Creative Commons Attribution 4.0 International License, which permits use, sharing, adaptation, distribution and reproduction in any medium or format, as long as you give appropriate credit to the original author(s) and the source, provide a link to the Creative Commons licence, and indicate if changes were made. The images or other third party material in this article are included in the article's Creative Commons licence, unless indicated otherwise in a credit line to the material. If material is not included in the article's Creative Commons licence and your intended use is not permitted by statutory regulation or exceeds the permitted use, you will need to obtain permission directly from the copyright holder. To view a copy of this licence, visit http://creativecommons.org/licenses/by/4.0/ The Creative Commons Public Domain Dedication waiver (http://creativecommons.org/publicdomain/zero/1.0/) applies to the data made available in this article, unless otherwise stated in a credit line to the data. 
prevalence of scoliosis had no difference in gender. However, the prevalence became higher in females when the curve progressed.

Due to the complicated development of scoliosis, the pathophysiological mechanism is debatable. Some studies $[10,11]$ indicated that it is related to genetic factors, endocrine abnormalities, nervous system dysfunction, abnormal growth and development, and any other factors, while other studies [12, 13] suggested that IS was mainly related to exercise and habitual posture. Adolescence is a period of the rapid development of scoliosis, but it is also a critical period for recovery and correction [14]. Adolescent scoliosis is a common spinal disease in adolescents, which is asymptomatic in its early stages and surgery is often required when spinal deformity occurs. Early screening to detect scoliosis can effectively prevent disease progression [15]. Therefore, attention should be paid to this period to reduce the pathogenic factors to scoliosis. Early screening, diagnosis, and intervention are important for the phased treatment of scoliosis.

There have been few reports of scoliosis prevalence based on large-scale morphological and epidemiological surveys among primary school children in the southeast coastal region of China. The aim of this study is to access the curve characteristics, prevalence, and the factors associated with IS by scoliosis screening and investigation among primary school students from grade 1 to 6 in Chaozhou city (Teochew), so as to provide clues for prevention, intervention, and treatment of IS and promotion of spinal health.

\section{Methods}

\section{Study design and subjects}

This study was divided into two stages. In the first stage, a cross-sectional study was carried out to survey the morphology and prevalence of IS among primary school students (grades 1 to 6) in Chaozhou city based on a cluster random sampling method from October to November, 2018. Scoliosis screening for these primary school students was performed based on available international methods (introducing below in detail).

In the second stage, a case-control study based on the screening survey was conducted, which involved the screening out scoliosis students as cases, and the students without scoliosis from the same classes as controls, to explore the factors associated with IS.

The study was approved by the human ethics committee of Shantou University Medical College. All participates were noticed of the contents of this study and attached with their privacy and confidentiality commitments utilizing voluntary.

\section{Scoliosis screening}

Screening criteria

Spine and chest deformities (including treatment with a brace), musculoskeletal anomalies, neurological disorders, and operation history were questioned and excluded from the study.

The screening method were (1) students were examined in an upright standing position to observe head lean, shoulder asymmetries, unequal inferior angle of the scapula, scapular prominence, waist asymmetries, or pelvis lean. (2) Adams' forward bending test (FBT) was examined to observe thorax asymmetries, scapular asymmetries, waist asymmetries, pelvis lean, and spinous process line is not in the longitudinal midline. Students with at least one positive test were inspected angle of trunk rotation (ATR), which was screened by the MeshLab 3D (ISTI-CNR) [16]. Furthermore, the inclusion criteria were that a curve progression of $\geq 3^{\circ}$ was used as ATR cut-off value and suspected of scoliosis. The standard Cobb method was used to measure X-ray examination, and cases with a Cobb angle of $\geq 10^{\circ}$ were accepted as scoliosis.

\section{Screening procedure}

The sample size of the screening was calculated as follows: $n=\frac{u_{\alpha}^{2} p q}{d^{2}}$, where $\mathrm{p}$ is the prevalence of scoliosis among primary school students, and value as $6 \%$ according to literature report; $d$ is the sensitivity level (margin error), $\mathrm{d}=0.15 \mathrm{p}$. Finally, we regard 3068 as the minimum sample size after increasing $10 \%$. The physical examination was performed by orthopedics and rehabilitation physicians to screen-positive patients. Then the first positive screening participants were recorded for the age, gender, class, ID number, and other information and taken the ATR as reference data. The suspected scoliosis students were performed an X-ray examination and were made a definite diagnosis according to the $\mathrm{X}$ ray results.

\section{Investigation on the factors associated with scoliosis in Chaozhou city}

Based on the previous screening results, we conducted a case-control study to explore the factors associated with

IS. The sample size was calculated as follows: $n$ $=\frac{\left(Z_{\alpha} \sqrt{2 \overline{p q}}+Z_{\beta} \sqrt{p_{0} q_{0}+p_{1} q_{1}}\right)^{2}}{\left(p_{1}-p_{0}\right)^{2}}$, where $p_{0}$ is the exposure rate of a related factor in the controls, and $p_{1}$ is the exposure rate of a related factor in the cases, $q_{0}=1-p_{0}, q_{1}=1-p_{1}$. We selected the variable "Having myopia" to calculate the sample size, and the needed number is 150 for the case group and control group, respectively. 
Table 1 The prevalence rates of idiopathic scoliosis among primary school children in Chaozhou, China

\begin{tabular}{llllll}
\hline $\begin{array}{l}\text { Age } \\
\text { (years) }\end{array}$ & Male & & & \multicolumn{2}{l}{ Female } \\
\cline { 2 - 3 } \cline { 5 - 6 } \cline { 5 - 6 } & $\mathbf{N}$ & Positive, $\mathbf{n}(\%)$ & & N & Positive, $\mathbf{n}(\%)$ \\
\hline 6 & 338 & $10(2.96)$ & 308 & $20(6.49)$ \\
7 & 457 & $16(3.50)$ & & 400 & $27(6.75)$ \\
8 & 490 & $21(4.29)$ & 388 & $33(8.51)$ \\
9 & 554 & $23(4.15)$ & 471 & $34(7.22)$ \\
10 & 502 & $21(4.18)$ & 428 & $31(7.24)$ \\
11 & 507 & $22(4.34)$ & 379 & $41(10.82)$ \\
12 & 170 & $9(5.29)$ & 105 & $30(28.57)$ \\
Total & 3018 & $122(4.04)$ & 2479 & $216(8.71)$ \\
\hline
\end{tabular}

A self-designed questionnaire was addressed to collect the following information: demographic characteristics, postural habits, cognition of scoliosis, self-sensation of scoliosis with symptoms, physical condition, sleeping time, exercise time, and any other factors. The questionnaire was revised twice following a pre-survey and consulting spine specialists and epidemiologists. The participant students were requested to finish the questionnaire in about $30 \mathrm{~min}$. If anyone could not understand any question, he/she would consult the trained teachers and investigators. After finished, the questionnaire was checked by the investigators at once, to avoid any questions being neglected.

\section{Statistical analysis}

The database was established with EpiData (Jens M. Lauritsen, Odense, Denmark)with double entry and validation to ensure consistency testing. The IBM SPSS Statistic 26.0 (IBM Corp., Armonk, NY, USA) was used to statistical analyses. Demographic data were analyzed by descriptive statistical methods. The results were expressed as the percentage value or mean \pm standard deviation. The continuous variables were performed by independent sample $t$ tests, and the categorical variables were performed by chi-squared tests. Logistic regression analysis was performed to explore the factors associated with scoliosis. All the statistical tests were two-sided, and $P<0.05$ was considered statistically significant.

\section{Results}

\section{Demographics of the participants}

Scoliosis screening was conducted on 5497 primary school students in Chaozhou city, including 2479 girls and 3018 boys (Table 1). In total, the positive rate of girls $(8.71 \%)$ was 2.16 times as many as boys (4.04\%). The prevalence rate increased with age, and the

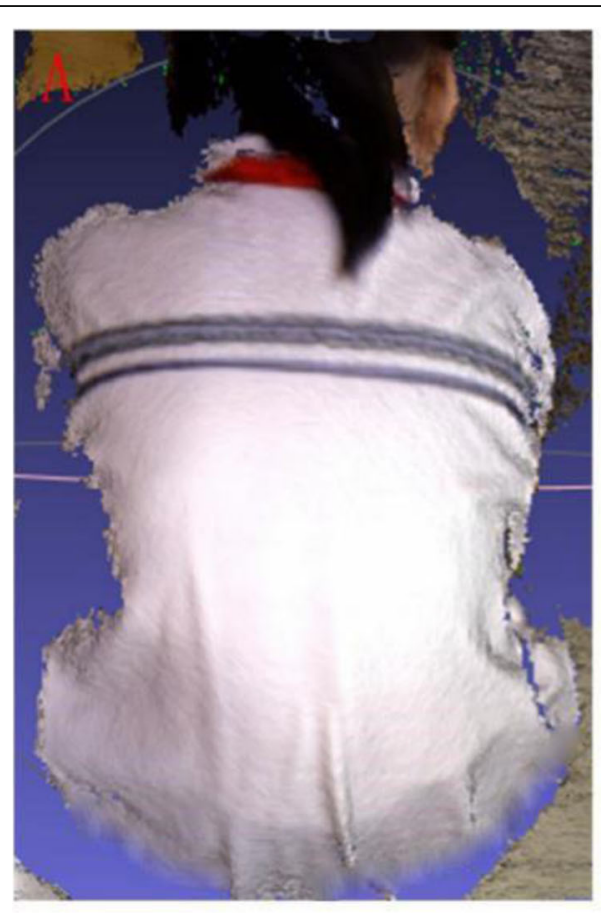

(A)

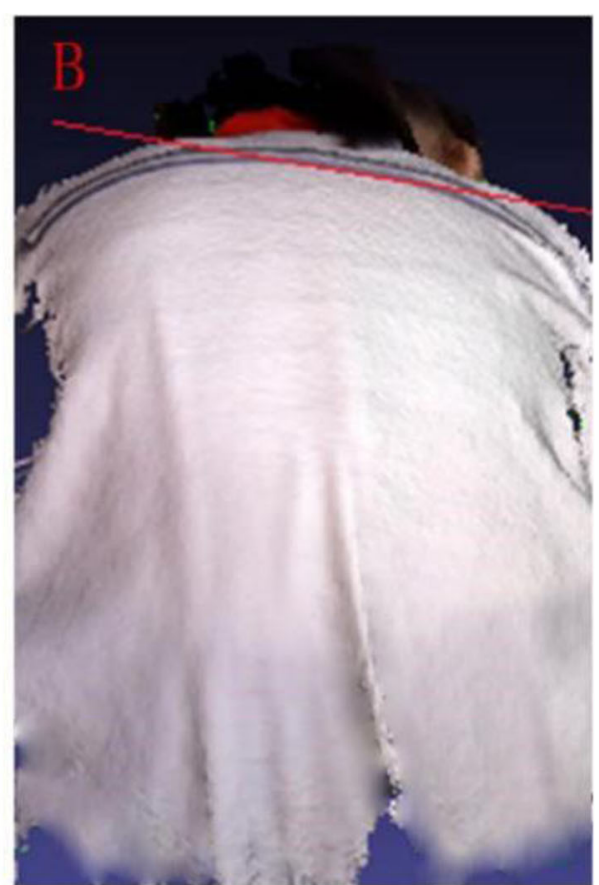

(B)

Fig. $13 D$ images of the back. A 3D image on the back. B An angle-adjusted 3D image. The line is the tangent of the plane of the chest and back, showing an obvious asymmetrical tilt of the chest and back 
prevalence in girls is all higher than in boys in different age groups $\left(\chi^{2}=51.45, P<0.001\right.$, Table 1$)$.

\section{D scanning on body surface}

In this study, 3D scanning on the back of all positive pre-screened subjects (338) was recorded at MeshLab $3 \mathrm{D}$. The 3D scanning was filtered to find the most obvious part of the back asymmetry and simulate the Scoliometer. The 3D images obtained in this screening showed that the minimum ART is $3^{\circ}$ and the maximum ART is $8^{\circ}$. Figure 1 shows the $3 \mathrm{D}$ image on the back of a female scoliosis case, and the surface tilt angle is measured at $4.8324^{\circ}$ (Fig. 2).

\section{ART of MeshLab 3D and Cobb angle of X-ray examination} A total of 12 screened positive patients participated in the reexamination, among which the minimum ART was $2.3^{\circ}$ and the maximum was $10.4^{\circ}$. The minimum Cobb angle of X-ray examination was $8^{\circ}$, and the maximum was $37^{\circ}$. The ART of 11 patients was $\geq 3^{\circ}$, with a positive rate of $91.67 \%$. The Cobb angle of 10 patients was $\geq 10^{\circ}$, with a positive rate of $83.33 \%$, and the accuracy rate was $84.62 \%$ (Table 2 ).

\section{Investigation on the factors associated with IS}

A total of 2550 questionnaires were collected, among which 2547 (1094 girls and 1453 boys) were valid, with an effective response rate of $99.8 \%$. Significant associations with IS were found in gender, weight, BMI, appetite, myopia, cognition of scoliosis, self-sensation of scoliosis with symptoms, sleep time, and exercise time (all $P<0.05$, Table 3).

Body coordination, vertebral discomfort, postural habits, and exercise methods between cases and controls were shown in Table 4. In terms of body coordination, $3.4 \%$ of the cases have the problem of asymmetrical back, $14.3 \%$ of the cases have hunchback, while $1.3 \%$ and $9.1 \%$, respectively, in the controls (both $P<0.05$ ). In the survey of vertebral discomfort, $42.3 \%$ of the cases had neck pain, which was higher than the controls $(33.2 \%$, $P=0.014)$. As to exercise methods, more IS cases engaged in badminton (54.3\% vs. $44.9 \%)$, but less engaged in basketball (24.0\% vs. $34.7 \%)$.

\section{Multifactorial analysis of correlative factors of IS}

Univariate logistic regression analysis models were used to explore the factors associated with IS. The results showed that gender, myopia, cognition of scoliosis, self-

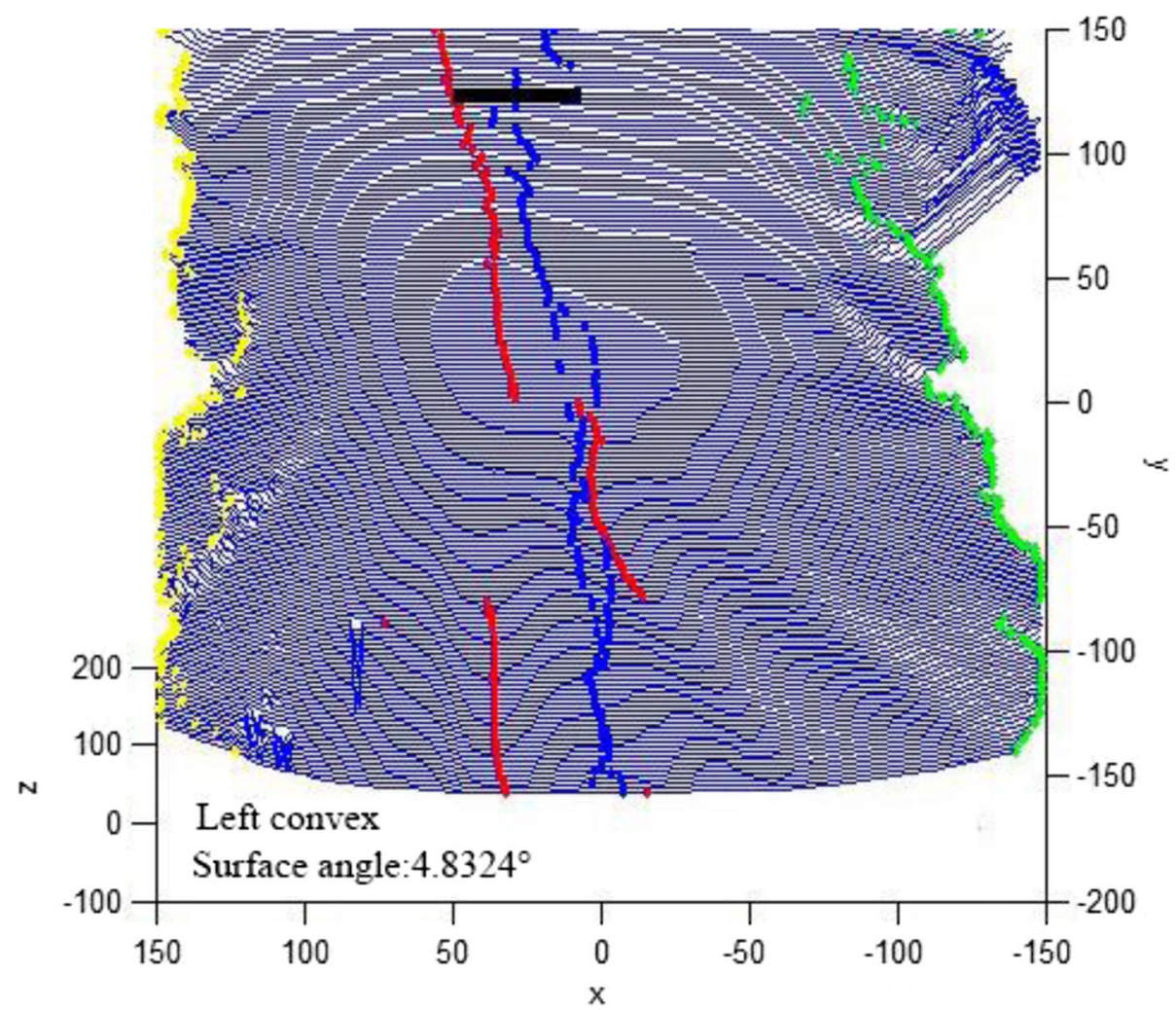

Fig. 2 3D scanning image on body surface. The thick black line in the image is where the asymmetry of the back is most pronounced and where the inclination of the surface is measured 
Table 2 Comparison of ART and Cobb angle

\begin{tabular}{llll}
\hline & & Cobb angle $\geq \mathbf{1 0}^{\circ}$ \\
\hline ATR $\geq 3^{\circ}$ & + & - \\
& + & 10 & 1 \\
& - & 0 & 1 \\
\hline
\end{tabular}

ATR $\geq 3$ was screening value; Cobb angle $\geq 10^{\circ}$ was confirming value

Table 3 Demographic characteristics of idiopathic scoliosis cases and controls

\begin{tabular}{llll}
\hline Variable & Cases $(\boldsymbol{n}=\mathbf{1 7 5})$ & Controls $(\boldsymbol{n}=\mathbf{2 3 7 2})$ & $\boldsymbol{P}$ \\
\hline Height $($ mean $\pm \mathrm{SD}, \mathrm{cm})$ & $142.64 \pm 12.89$ & $141.64 \pm 12.78$ & 0.323 \\
Weight $($ mean $\pm \mathrm{SD}, \mathrm{kg})$ & $32.74 \pm 8.28$ & $34.35 \pm 10.32$ & 0.045 \\
$\mathrm{BMI}\left(\right.$ mean $\left.\pm \mathrm{SD}, \mathrm{kg} / \mathrm{cm}^{2}\right)$ & $16.03 \pm 3.22$ & $16.91 \pm 3.95$ & 0.004 \\
Gender & & & \\
$\quad$ Female & $116(66.3)$ & $978(41.2)$ & $<0.001$ \\
$\quad$ Male & $59(33.7)$ & $1394(58.8)$ & \\
Appetite & & & \\
$\quad$ Bad & $3(1.7)$ & $111(4.7)$ & 0.034 \\
$\quad$ General & $117(66.9)$ & $1379(58.1)$ & \\
$\quad$ Good & $55(31.4)$ & $882(37.2)$ & \\
Having myopia & & & 0.002 \\
No & $112(64.0)$ & $1774(74.8)$ & \\
$\quad$ Yes & $63(36.0)$ & $598(25.2)$ &
\end{tabular}

Have a habit of carrying a backpack on one shoulder

$\begin{array}{lll}\text { Sometimes } & 54(30.9) & 758(32.0) \\ \text { No } & 110(62.9) & 1375(58.0) \\ \text { Yes } & 11(6.3) & 238(10.0) \\ \text { Cognition of scoliosis } & & \\ \text { Never known } & 58(33.1) & 1231(51.9) \\ \text { Have heard } & 62(35.4) & 687(29.0) \\ \text { Known } & 55(31.4) & 453(19.1)\end{array}$

Self-sensation of scoliosis with symptoms

\begin{tabular}{llll} 
No & $65(37.1)$ & $1142(48.2)$ & $<0.001$ \\
Not clear & $83(47.4)$ & $1136(47.9)$ & \\
Yes & $27(15.4)$ & $93(3.9)$ & \\
Sleep time & & & \\
$\quad$ More than $10 \mathrm{~h}$ & $2(1.1)$ & $117(4.9)$ & 0.049 \\
8 to $10 \mathrm{~h}$ & $156(89.1)$ & $1995(84.1)$ & \\
Less than $8 \mathrm{~h}$ & $17(9.8)$ & $260(11.0)$ & 0.036 \\
Daily exercise duration & & & \\
More than 3 h & $1(0.6)$ & $117(4.9)$ & \\
2 to $3 \mathrm{~h}$ & $10(5.7)$ & $175(7.4)$ & $869(36.7)$ \\
1 to $2 \mathrm{~h}$ & $63(36.2)$ & $1209(51.0)$ & \\
Less than $1 \mathrm{~h}$ & $100(57.5)$ & & \\
\hline
\end{tabular}

Data are no. (\%) unless indicated. Independent sample $t$ test was used for the continuous variables, and chi-squared test or Fisher's exact test was used for categorical data sensation of scoliosis with symptoms, sleep time, and daily exercise duration were all related to the occurrence of IS (all $P<0.05$, Table 5).

In the multiple logistic regression analysis model, females had more likelihood to develop IS $(\mathrm{OR}=2.45$, 95\%CI 1.71-3.36); myopia children presented 1.49 times (95\%CI 1.05-2.11) higher likelihood of IS, when compared to children without myopia. With the BMI of the children increasing, the IS decreased ( $\mathrm{OR}=0.67,95 \% C I$ $0.23-0.89$ ). The IS cases had more self-sensation of scoliosis symptoms $(\mathrm{OR}=5.52,95 \% C I$ 3.27-9.29). The likelihood of scoliosis increased gradually as the sleep time decreased, and those who sleep less than $8 \mathrm{~h}$ were 3.33 times (95\%CI 1.51-10.64) greater likelihood than those with more than $10 \mathrm{~h}$ a day. With the increase of exercise time, the likelihood of scoliosis decreased gradually, and those who exercised less than $1 \mathrm{~h}$ were 7.29 times (95\%CI 1.99-53.37) greater likelihood than those with $3 \mathrm{~h}$ a day (Table 6).

\section{Discussion}

This study was conducted to survey the IS prevalence among primary school-aged children in Chaozhou, Southeast of China, and further investigate the factors associated with IS, which was the first time to screen IS in primary school students based on a large-scale epidemiological study. The results indicated that the prevalence of IS among primary school students in Chaozhou was $6.15 \%$, with $4.04 \%$ in males and $8.71 \%$ in females. In addition, the prevalence of IS increased with age. The female students, with more possibility of trunk asymmetry, had a higher prevalence than the males. Many factors such as BMI, myopia, cognition of scoliosis, selfsensation of scoliosis with symptoms, sleep time, and exercise time were associated significantly with scoliosis.

\section{Gender, age-related prevalence}

Our study indicated that females had more possibility to suffer from IS. As reported in literature elsewhere, IS was more common in females. Adolescent girls are easier to suffer from idiopathic scoliosis because the curvature of the spine progress in puberty, and females enter physiological puberty early. Another reason is that boys are more motivated than girls when it comes to doing physical exercise [17], except in relation to weight and body image and agility or flexibility, which is superior in the female gender. The reduced body weight, especially in girls, strongly predisposes the occurrence of scoliosis. In the annual observation, the girls who had trunk asymmetry, in order to decrease the ATR value, cannot significantly increase their body weight [18]. The studies $[19,20]$ showed that adolescents with scoliosis were taller than other adolescents in the same age group, and a growth velocity of more than 2 $\mathrm{cm}$ per year was associated with curve progression. It is 
Table 4 Distribution of body coordination, vertebral discomfort, postural habits, and exercise adopted in daily activities in participants

\begin{tabular}{|c|c|c|c|}
\hline Variables & Cases $(n=175)$ & Controls $(n=2372)$ & $P$ \\
\hline \multicolumn{4}{|l|}{ Body coordination } \\
\hline Shoulder asymmetries & $8(4.6)$ & $77(3.2)$ & 0.346 \\
\hline Unequal length of legs & $1(0.6)$ & $41(1.7)$ & 0.361 \\
\hline Asymmetrical back & $6(3.4)$ & $31(1.3)$ & 0.038 \\
\hline Hunchback & $25(14.3)$ & $217(9.1)$ & 0.025 \\
\hline Crooked neck & $8(4.6)$ & $60(2.5)$ & 0.137 \\
\hline \multicolumn{4}{|l|}{ Vertebral discomfort } \\
\hline Neck pain & $74(42.3)$ & $787(33.2)$ & 0.014 \\
\hline Chest pain & $17(9.7)$ & $298(12.6)$ & 0.269 \\
\hline Waist pain & $37(21.1)$ & 464 (19.6) & 0.612 \\
\hline \multicolumn{4}{|l|}{ Postural habits } \\
\hline Write or read on your stomach & $32(18.3)$ & $442(18.6)$ & 0.909 \\
\hline Curl up with a book & $15(8.6)$ & $162(6.8)$ & 0.382 \\
\hline Sleep on one side & $109(62.3)$ & $1340(56.5)$ & 0.135 \\
\hline Paralyzed sitting & $13(7.4)$ & $169(7.1)$ & 0.880 \\
\hline Sleep on your stomach & $18(10.3)$ & $371(15.6)$ & 0.057 \\
\hline Cross your legs & $20(11.4)$ & $295(12.4)$ & 0.696 \\
\hline Watch TV in bed & $28(16.0)$ & $349(14.7)$ & 0.644 \\
\hline Play mobile phone in bed & $60(34.3)$ & 947 (39.9) & 0.141 \\
\hline \multicolumn{4}{|l|}{ Exercise methods } \\
\hline Badminton & $95(54.3)$ & 1065 (44.9) & 0.016 \\
\hline Basketball & $42(24.0)$ & $824(34.7)$ & 0.004 \\
\hline Football & $20(11.4)$ & 269 (11.3) & 0.972 \\
\hline Table tennis & $20(11.4)$ & $313(13.2)$ & 0.503 \\
\hline Shuttlecock & $7(4.0)$ & $87(3.7)$ & 0.822 \\
\hline Dance & $31(17.7)$ & $331(14.0)$ & 0.169 \\
\hline Roller skating & $43(24.6)$ & $536(22.6)$ & 0.548 \\
\hline Ride on a bicycle & $132(75.4)$ & 1708 (72.0) & 0.329 \\
\hline Chinese Kungfu & $13(7.4)$ & $239(10.1)$ & 0.258 \\
\hline Running & $102(58.3)$ & $1434(60.5)$ & 0.571 \\
\hline Swimming & $63(36.0)$ & 877 (37.0) & 0.797 \\
\hline
\end{tabular}

Data are no. (\%) unless indicated. Chi-squared test or Fisher's exact test was used for categorical data

believed that the increased prevalence of scoliosis in girls compared to boys is justified by the fact that girls tend to grow more than boys from ages 11 to 13 [21]. The ratio of females to males was reported to range from 2.3 to 18 [22-24]. The previous studies $[25,26]$ reported that females had a higher prevalence in all age groups than that in males, and both genders had a higher prevalence in the age group 15-16 after puberty, which is consistent with our study.

\section{Weight, BMI, and IS}

Weight is one of the important indexes to reflect a children's health condition. The average weight of the IS cases is $32.74 \pm 8.28 \mathrm{~kg}$, which is less than that of the controls $(34.35 \pm 10.32 \mathrm{~kg})$. At the developmental stage of a child, weight can reflect the nutritional status, muscle development, and bone development to some degree. BMI was a more comprehensive index of reflecting the body shape. The BMI of the IS cases is $16.03 \pm 3.22 \mathrm{~kg} /$ $\mathrm{m}^{2}$, which is also less than that of the controls $(16.91 \pm$ $3.95 \mathrm{~kg} / \mathrm{m}^{2}$ ), but both fall within the normal range of the national standard for students' physical health. The study [27] indicated a population-based prospective study, and the results suggested that BMI/body weight at age 10 and scoliosis at age 15 had a negative association, with per SD increase in BMI 20\% reduced risk of 
Table 5 Univariate logistic regression analysis of the factors associated with idiopathic scoliosis

\begin{tabular}{|c|c|c|c|}
\hline Variable & $P$ & $O R$ & $95 \% \mathrm{Cl}$ \\
\hline \multicolumn{4}{|l|}{ Gender } \\
\hline Male & & 1.0 & (Reference) \\
\hline Female & $<0.001$ & 2.80 & $(2.03,3.87)$ \\
\hline \multicolumn{4}{|l|}{ Having myopia } \\
\hline No & & 1.0 & (Reference) \\
\hline Unclear & 0.524 & 0.85 & $(0.52,1.40)$ \\
\hline Yes & 0.005 & 1.62 & $(1.16,2.26)$ \\
\hline \multicolumn{4}{|c|}{ Keep good posture while reading } \\
\hline No & & 1.0 & (Reference) \\
\hline Yes & 0.947 & 1.01 & $(0.74,1.37)$ \\
\hline \multicolumn{4}{|c|}{ Relax back after sitting for a long time } \\
\hline Never & & 1.0 & (Reference) \\
\hline Sometimes & 0.284 & 1.24 & $(0.84,1.83)$ \\
\hline Usually & 0.817 & 0.94 & $(0.55,1.60)$ \\
\hline \multicolumn{4}{|c|}{ Self-sensation of scoliosis with symptoms } \\
\hline No & & 1.0 & (Reference) \\
\hline Not clear & 0.144 & 1.28 & $(0.92,1.79)$ \\
\hline Yes & $<0.001$ & 5.101 & $(3.11,8.38)$ \\
\hline \multicolumn{4}{|l|}{ Sleep time } \\
\hline 10 to $11 \mathrm{~h}$ & & 1.0 & (Reference) \\
\hline 9 to $10 \mathrm{~h}$ & 0.043 & 4.38 & $(1.05,18.35)$ \\
\hline 8 to $9 \mathrm{~h}$ & 0.105 & 3.22 & $(0.78,13.26)$ \\
\hline Less than $8 \mathrm{~h}$ & 0.219 & 2.54 & $(0.57,11.28)$ \\
\hline \multicolumn{4}{|c|}{ Duration of reading } \\
\hline More than $3 \mathrm{~h}$ & & 1.0 & (Reference) \\
\hline 2 to $3 \mathrm{~h}$ & 0.820 & 0.92 & $(0.44,1.93)$ \\
\hline 1 to $2 \mathrm{~h}$ & 0.503 & 0.79 & $(0.40,1.57)$ \\
\hline Less than $1 \mathrm{~h}$ & 0.929 & 0.97 & $(0.48,1.97)$ \\
\hline \multicolumn{4}{|c|}{ Duration of exercise } \\
\hline More than $3 \mathrm{~h}$ & & 1.0 & (Reference) \\
\hline 2 to $3 \mathrm{~h}$ & 0.072 & 6.69 & $(0.85,52.93)$ \\
\hline 1 to $2 \mathrm{~h}$ & 0.035 & 8.48 & $(1.17,61.73)$ \\
\hline Less than $1 \mathrm{~h}$ & 0.025 & 9.68 & $(1.34,70.01)$ \\
\hline
\end{tabular}

$O R$ odds ratio, $95 \% \mathrm{Cl}$ confidence interval for $O R$

scoliosis. Worthington et al .[28] indicated that malnutrition might play a crucial part in the etiology of IS. But nutrition covers a wide range of areas that still need to be studied in conjunction with other indicators.

\section{Myopia and IS}

Students with myopia presented 1.49 times more possibility of IS, when compared with students who did not have myopia. It can be considered as a process of mutual or simultaneous development. Incorrect posture will
Table 6 Multiple logistic regression analysis of the factors associated with idiopathic scoliosis

\begin{tabular}{|c|c|c|c|}
\hline Variables & $P$ & $O R$ & $95 \% \mathrm{Cl}$ \\
\hline Gender (female vs. male) & $<0.001$ & 2.45 & $(1.71,3.36)$ \\
\hline BMl & 0.032 & 0.67 & $(0.23,0.89)$ \\
\hline \multicolumn{4}{|l|}{ Having myopia } \\
\hline No & & 1.0 & (Reference) \\
\hline Yes & 0.026 & 1.49 & $(1.05,2.11)$ \\
\hline \multicolumn{4}{|l|}{ Self-sensation of scoliosis } \\
\hline No & & 1.0 & (Reference) \\
\hline Not clear & 0.249 & 1.23 & $(0.87,1.74)$ \\
\hline Yes & $<0.001$ & 5.52 & $(3.27,9.29)$ \\
\hline \multicolumn{4}{|l|}{ Sleep time } \\
\hline More than $10 \mathrm{~h}$ & & 1.0 & (Reference) \\
\hline 8 to $10 \mathrm{~h}$ & 0.039 & 2.65 & $(1.08,19.97)$ \\
\hline Less than $8 \mathrm{~h}$ & 0.014 & 3.33 & $(1.51,10.64)$ \\
\hline \multicolumn{4}{|l|}{ Duration of exercise } \\
\hline More than $3 \mathrm{~h}$ & & 1.0 & (Reference) \\
\hline 2 to $3 \mathrm{~h}$ & 0.103 & 5.39 & $(0.67,43.25)$ \\
\hline 1 to $2 \mathrm{~h}$ & 0.045 & 7.09 & $(1.06,52.17)$ \\
\hline Less than $1 \mathrm{~h}$ & 0.025 & 7.29 & $(1.99,53.37)$ \\
\hline
\end{tabular}

increase the likelihood of scoliosis and lead to impaired vision. The major cardinal feature is joint hypermobility, or ligamentous laxity, $[29,30]$. In the absence of vision rectification, the impaired vision will promote the creation of forced posture, which in turn exacerbated the occurrence of scoliosis [31]. This is in line with Egorova's [32] study, which found that the musculoskeletal system of high myopia and impaired vision school-age children was more distorted than the controls, including scoliosis, pelvic dislocation, kyphosis, lordosis, torsion of the column, flatfoot, lower limb, and chest deformation.

\section{Cognition and self-sensation of scoliosis}

The IS cases had higher self-sensation of scoliosis symptoms. The most common scoliosis symptoms are physical asymmetry, back pain injury, muscle spasms, and others. According to the studies [33, 34], idiopathic scoliosis may result in a difference in leg length which regards that the difference in leg length can lead to compensated non-progressive lumbar scoliosis. In the published study [35], smaller leg length differences $(\leq 2 \mathrm{~cm})$ may lead to functional or non-fixed scoliosis, which should not be overlooked by medical professionals. Postural imbalances caused by muscle spasms, injury, pain, or any other factor s[36] can also develop into unstructured scoliosis, which is generally considered to be inconsequential [37]. However, if functional scoliosis is not diagnosed and corrected in puberty, it may 
eventually develop into pathological scoliosis [38]. Even if the screening results were normal, students with physical asymmetry still need to be paid great attention to, especially in puberty.

The cognition and sensation of deformity with IS should be considered cautiously, for the best treatment methods can be applied to reduce the spine curvature or stop the progression of IS $[39,40]$. Having good cognition help students redress their bad habits and took corrective measures initiatively. In theory, good posture can reduce the asymmetrical load of column deformity and reverse the vicious cycle of column curvature. Incorrect postures are common in daily life, which will increase the load of column asymmetry [41].

\section{Sleep time, exercise time, and IS}

Scoliosis patients have an unbalanced load that may lead to skeletal muscle fatigue and require more sleep to regain strength [42]. From another perspective, most muscles are relaxed when people are lying. The most obvious change after standing up is the erector spine, which is an important muscle for keeping the body upright and maintaining the stability and balance of the crista e[43]. Long time lying may lead to poor vertical stress training and muscle strength or endurance of skeletal muscl e[44]. The study [45] showed that decreasing sleep duration results in overexpression of IL-1 and lower bone mineral density and might increase the spine curvature. Furthermore, the relationship of scoliosis, class II malocclusion, and obstructive sleep apnea is worth discussing. The study [46] showed that the forward head posture associated with scoliosis may lead to stretching of the muscles, skin, and fascia covering the head and neck, impeding the sagittal growth of the mandible and facial skeleton, which leads to class II malocclusion. Besides, class II malocclusion has been reported as a dental feature associated with obstructive sleep apnea which could explain sleeping disturbances in IS patients [47]. The stud y[48] suggested that sleep screening should be taken into consideration for the evaluation and treatment of patients with early-onset scoliosis, because poor-quality and inadequate sleep has a bad influence on children' behavior, cognitive function, and growth.

With the increase of exercise time, the likelihood of scoliosis decreased gradually, and those who exercised less than $1 \mathrm{~h}$ were 7.29 times more likelihood than those with $3 \mathrm{~h}$ a day. Since it is found that biomechanics are relative to unbalanced loads and time thresholds, we can reverse the asymmetrical load by restoring normal postures and exercise. According to the study [49], exercise can reduce the prevalence of scoliosis and patients Cobb angle, especially in early adolescence, because exercise can improve mobility, strength, breathing, and equilibrium. The study [50] confirmed the efficacy of exercises can reduce spine curvature (mainly in puberty) and improve the Cobb angle. The study [51,52] showed the effectiveness of spinal stabilization exercises on pain reductions for adolescents with idiopathic scoliosis.

\section{Limitation and strength}

This study has several limitations. Firstly, X-ray examination was not performed immediately because of low compatibility and lack of attention. Secondly, the crosssectional study could not establish the cause-and-effect relationship, while a longitudinal approach might help research the development of the relationship. Third, the number of participants in the case-control study was reduced because it was conducted seven months after screening. Despite these limitations, FBT and ATR of 3D images used in the survey could help us increase the accuracy and objectivity of the screening. More adolescents and age phases are needed to be investigated in the future based on large-scale epidemiological studies to reach more scientific conclusions. To our knowledge, this is the first study conducted in Chaozhou city to screen and investigate influencing factors of IS in primary school children. In the future, a wider group of predictors and broader age groups should be brought into study, to collect more epidemiological data and more clues for the scoliosis intervention.

\section{Conclusions}

Scoliosis is still common in primary school students due to multiple influencing factors. IS prevalence among female students in Chaozhou city is significantly higher than that of males. Besides, lower body mass, having myopia, insufficient sleep time, and lower physical activity are associated with IS. Since the prevalence of IS increases with age, early screening should be carried out before puberty, especially in adolescent females.

\section{Abbreviations}

IS: Idiopathic scoliosis; FBT: Adams' forward bending test; ATR: Angle of trunk rotation; BMI: Body mass index

\section{Acknowledgements \\ The authors thank all the children, parents, teachers, and schools who} participated in this project.

\section{Authors' contributions}

Conceptualization, K.W., R.W. and Z.C.; methodology, K.W. and R.W.; software, R.W. and Z.C.; formal analysis, Z.C.; investigation, Z.C., S.Z. and Z.Q.; resources, R.W.; data curation, Z.C. and Z.Q.; writing-original draft preparation, R.W. and Z.C.; writing - review and editing, K.W. and Z.C.; visualization, Z.C. and S.Z.; project administration, Z.Q. The authors read and approved the final manuscript.

\section{Funding}

This study was funded by the Natural Science Foundation of Guangdong Province (No.: 2019A1515010891). 


\section{Availability of data and materials}

The datasets used and/or analyzed during the current study are available from the corresponding author on reasonable request.

\section{Declarations}

\section{Ethics approval and consent to participate}

All participants gave their informed written consent after receiving detailed explanations of the study. This study was performed with the approval of the Human Ethical Committee of Shantou University Medical College.

\section{Consent for publication}

Not applicable.

\section{Competing interests}

The authors declare that they have no competing interests.

\section{Author details}

'Department of Preventive Medicine, Shantou University Medical College, No.22, Xinling Rd, Shantou 515041, Guangdong Province, China. ${ }^{2}$ Chaozhou People's Hospital, Chaozhou 521000, Guangdong Province, China.

Received: 8 March 2021 Accepted: 13 June 2021

Published online: 03 July 2021

\section{References}

1. Altaf F, Gibson A, Dannawi Z, Noordeen H. Adolescent idiopathic scoliosis. Bmj. 2013;346:f2508. https://doi.org/10.1136/bmj.f2508.

2. Shen J, Lin Y, Luo J, Xiao Y. Cardiopulmonary Exercise testing in patients with idiopathic scoliosis. J Bone Joint Surg Am. 2016;98(19):1614-22. https:// doi.org/10.2106/jbjs.15.01403.

3. Weinstein SL, Dolan LA, Spratt KF, Peterson KK, Spoonamore MJ, Ponseti IV. Health and function of patients with untreated idiopathic scoliosis: a 50year natural history study. Jama. 2003;289(5):559-67. https://doi.org/10.1001/ jama.289.5.559.

4. Qiu Y, Yin G, Wang B, Zhu F, Sun X, Sun GQ, et al. Classification of thoracic pedicle according to the transverse diameters in thoracic idiopathic scoliosis patients and its clinical significance. Zhonghua Wai Ke Za Zhi. 2010; 48(5):353-7.

5. Heemskerk JL, Kruyt MC, Colo D, Castelein RM, Kempen DHR. Prevalence and risk factors for neural axis anomalies in idiopathic scoliosis: a systematic review. Spine J. 2018;18(7):1261-71. https://doi.org/10.1016/j.spinee.2018.02. 013.

6. Moalej S, Asadabadi M, Hashemi R, Khedmat L, Tavacolizadeh R, Vahabi Z, et al. Screening of scoliosis in school children in Tehran: the prevalence rate of idiopathic scoliosis. J Back Musculoskelet Rehabil. 2018;31(4):767-74. https://doi.org/10.3233/bmr-171078.

7. Penha PJ, Ramos N, de Carvalho BKG, Andrade RM, Schmitt ACB, Joao SMA Prevalence of adolescent idiopathic scoliosis in the State of Sao Paulo, Brazil. Spine. 2018;43(24):1710-8. https://doi.org/10.1097/brs.0000000000002 725.

8. Hresko MT, Talwalkar V, Schwend R. Early detection of idiopathic scoliosis in adolescents. J Bone Joint Surg Am. 2016;98(16):e67. https://doi.org/10.2106/ jbjs.16.00224.

9. Asher MA, Burton DC. Adolescent idiopathic scoliosis: natural history and long term treatment effects. Scoliosis. 2006;1(1):2. https://doi.org/10.1186/1 748-7161-1-2.

10. Peng Y, Wang SR, Qiu GX, Zhang JG, Zhuang QY. Research progress on the etiology and pathogenesis of adolescent idiopathic scoliosis. Chin Med J. 2020;133(4):483-93. https://doi.org/10.1097/cm9.0000000000000652.

11. Kouwenhoven JW, Castelein RM. The pathogenesis of adolescent idiopathic scoliosis: review of the literature. Spine. 2008;33(26):2898-908. https://doi. org/10.1097/BRS.0b013e3181891751.

12. Penha PJ, Penha NLJ, De Carvalho BKG, Andrade RM, Schmitt ACB, João SMA. Posture alignment of adolescent idiopathic scoliosis: photogrammetry in scoliosis school screening. J Manip Physiol Ther. 2017:40(6):441-51. https://doi.org/10.1016/j.jmpt.2017.03.013.

13. Barrios C, Pérez-Encinas C, Maruenda Jl, Laguía M. Significant ventilatory functional restriction in adolescents with mild or moderate scoliosis during maximal exercise tolerance test. Spine. 2005;30(14):1610-5. https://doi.org/1 0.1097/01.brs.0000169447.55556.01
14. Nissinen MJ, Heliovaara MM, Seitsamo JT, Kononen MH, Hurmerinta KA, Poussa MS. Development of trunk asymmetry in a cohort of children ages 11 to 22 years. Spine. 2000;25(5):570-4. https://doi.org/10.1097/00007632-2 00003010-00007.

15. Chinese Society of Osteology Spinal Surgery Group. Guidelines for clinical practice and pathway of scoliosis screening in Chinese adolescents. Chin J Orthopaedics. 2020;40(23):1574-82.

16. Yilmaz H, Zateri C, Kusvuran Ozkan A, Kayalar G, Berk H. Prevalence of adolescent idiopathic scoliosis in Turkey: an epidemiological study. Spine J. 2020;20(6):947-55. https://doi.org/10.1016/j.spinee.2020.01.008.

17. Portela-Pino I, López-Castedo A, Martínez-Patiño MJ, Valverde-Esteve T, Domínguez-Alonso J. Gender differences in motivation and barriers for the practice of physical exercise in adolescence. Int J Environ Res Public Health. 2019;17(1):168. https://doi.org/10.3390/ijerph17010168.

18. Adamczewska K, Wiernicka M, Kamińska E, Małecka J, Dąbrowska A Malchrowicz-Mośko E. Annual observation of changes in the angle of trunk rotation. Trunk asymmetry predictors. A study from a scoliosis screening in school adolescents. Int J Environ Res Public Health. 2020, 1899;17(6). https:// doi.org/10.3390/ijerph17061899.

19. Ylikoski M. Height of girls with adolescent idiopathic scoliosis. Eur Spine J. 2003:12(3):288-91. https://doi.org/10.1007/s00586-003-0527-x.

20. Ylikoski M. Growth and progression of adolescent idiopathic scoliosis in girls. J Pediatr Orthop B. 2005;14(5):320-4. https://doi.org/10.1097/012 02412-200509000-00002.

21. Wei-Jun W, Xu S, Zhi-Wei W, Xu-Sheng Q, Zhen L, Yong Q. Abnormal anthropometric measurements and growth pattern in male adolescent idiopathic scoliosis. Eur Spine J. 2012;21(1):77-83. https://doi.org/10.1007/ s00586-011-1960-x.

22. Lee JY, Moon SH, Kim HJ, Park MS, Suh BK, Nam JH, et al. The prevalence of idiopathic scoliosis in eleven year-old Korean adolescents: a 3 year epidemiological study. Yonsei Med J. 2014;55(3):773-8. https://doi.org/1 0.3349/ymj.2014.55.3.773.

23. Ueno M, Takaso M, Nakazawa T, Imura T, Saito W, Shintani R, et al. A 5-year epidemiological study on the prevalence rate of idiopathic scoliosis in Tokyo: school screening of more than 250,000 children. J Orthop Sci. 2011; 16(1):1-6. https://doi.org/10.1007/s00776-010-0009-z.

24. Grivas TB, Koukos K, Koukou UI, Maziotou C, Polyzois BD. The incidence of idiopathic scoliosis in Greece--analyais of domestic school screening programs. Stud Health Technol Inform. 2002;91:71-5.

25. Konieczny MR, Senyurt $H$, Krauspe R. Epidemiology of adolescent idiopathic scoliosis. J Child Orthop. 2013;7(1):3-9. https://doi.org/10.1007/s11832-0120457-4.

26. Zheng Y, Dang Y, Wu X, Yang Y, Reinhardt JD, He C, et al. Epidemiological study of adolescent idiopathic scoliosis in Eastern China. J Rehabil Med. 2017:49(6):512-9. https://doi.org/10.2340/16501977-2240.

27. Clark EM, Taylor HJ, Harding I, Hutchinson J, Nelson I, Deanfield JE, et al. Association between components of body composition and scoliosis: a prospective cohort study reporting differences identifiable before the onset of scoliosis. J Bone Miner Res. 2014;29(8):1729-36. https://doi.org/10.1002/ jbmr.2207.

28. Worthington $V$, Shambaugh P. Nutrition as an environmental factor in the etiology of idiopathic scoliosis. J Manip Physiol Ther. 1993;16(3):169-73.

29. Elsebaie HB, Dannawi Z, Altaf F, Zaidan A, Al Mukhtar M, Shaw MJ, et al. Clinically orientated classification incorporating shoulder balance for the surgical treatment of adolescent idiopathic scoliosis. Eur Spine J. 2016;25(2): 430-7. https://doi.org/10.1007/s00586-015-4090-z.

30. Armon K, Bale P. Identifying heritable connective tissue disorders in childhood. Practitioner. 2012;256(1752):19-23 2-3.

31. Pärssinen $\mathrm{O}$, Kauppinen $\mathrm{M}$. Associations of reading posture, gaze angle and reading distance with myopia and myopic progression. Acta Ophthalmol. 2016;94(8):775-9. https://doi.org/10.1111/aos.13148.

32. Egorova TS, Smirnova TS, Romashin OV, Egorova IV. Deformations of the vertebral column in the visually impaired schoolchildren presenting with complicated high myopia and the possibilities for its correction. Vopr Kurortol Fizioter Lech Fiz Kult. 2016;93(2):20-5. https://doi.org/10.17116/ kurort2016220-25.

33. Sekiya T, Aota Y, Yamada K, Kaneko K, Ide M, Saito T. Evaluation of functional and structural leg length discrepancy in patients with adolescent idiopathic scoliosis using the EOS imaging system: a prospective comparative study. Scoliosis Spinal Disord. 2018;13(1):7. https://doi.org/10.11 86/s13013-018-0152-4 
34. Papaioannou T, Stokes I, Kenwright J. Scoliosis associated with limb-length inequality. J Bone Joint Surg Am. 1982;64(1):59-62. https://doi.org/10.2106/ 00004623-198264010-00009.

35. Raczkowski JW, Daniszewska B, Zolynski K. Functional scoliosis caused by leg length discrepancy. Arch Med Sci. 2010;6(3):393-8. https://doi.org/10. 5114/aoms.2010.14262.

36. Nussinovitch M, Finkelstein Y, Amir J, Greenbaum E, Volovitz B. Adolescent screening for orthopedic problems in high school. Public Health. 2002; 116(1):30-2. https://doi.org/10.1038/sj/ph/1900812.

37. Hawes MC, O'Brien JP. The transformation of spinal curvature into spinal deformity: pathological processes and implications for treatment. Scoliosis. 2006;1 (1):3. https://doi.org/10.1186/1748-7161-1-3.

38. Karski T. Biomechanical factors in the etiology of idiopathic scoliosis: two etiopathological groups of spinal deformities. Ortop Traumatol Rehabil. 2004;6(6):800-8.

39. Matamalas A, D'Agata E, Sanchez-Raya J, Bago J. Trunk appearance perception scale for physicians (TAPS-Phy) - a valid and reliable tool to rate trunk deformity in idiopathic scoliosis. Scoliosis Spinal Disord. 2016;11(1):24. https://doi.org/10.1186/s13013-016-0085-8.

40. Colak TK, Akgul T, Colak I, Dereli EE, Chodza M, Dikici F. Health related quality of life and perception of deformity in patients with adolescent idiopathic scoliosis. J Back Musculoskelet Rehabil. 2017;30(3):597-602. https://doi.org/10.3233/bmr-160564.

41. Weiss HR, Moramarco MM, Borysov M, Ng SY, Lee SG, Nan X, et al. Postural rehabilitation for adolescent idiopathic scoliosis during growth. Asian Spine J. 2016:10(3):570-81. https://doi.org/10.4184/asj.2016.10.3.570.

42. Vitale JA, Negrini F, Rebagliati G, Giacomelli L, Donzelli S, Banfi G. Actigraphy-based sleep parameters and rest-activity circadian rhythm in a young scoliotic patient treated with rigid bracing: a case study. Yale J Biol Med. 2019;92(2):205-12.

43. Burke D, Adams RW, Skuse NF. The effects of voluntary contraction on the H reflex of human limb muscles. Brain. 1989;112(Pt 2):417-33. https://doi. org/10.1093/brain/112.2.417.

44. Saey D, Troosters T. Measuring skeletal muscle strength and endurance, from bench to bedside. Clin Invest Med. 2008;31(5):E307-11. https://doi. org/10.25011/cim.v31i5.4881.

45. Li H, Liang C, Shen C, Li Y, Chen Q. Decreased sleep duration: a risk of progression of degenerative lumbar scoliosis. Med Hypotheses. 2012;78(2): 244-6. https://doi.org/10.1016/..mehy.2011.10.036.

46. Głowacka J, Opydo-Szymaczek J, Mehr K, Pawlaczyk-Kamieńska T, Głowacki J. Adolescent idiopathic scoliosis and malocclusion - a cross sectional study of female patients without previous orthodontic treatment. Anthropol Anz. 2020;77(4):269-80. https://doi.org/10.1127/anthranz/2020/1198.

47. Banabilh SM. Orthodontic view in the diagnoses of obstructive sleep apnea. J Orthod Sci. 2017:6(3):81-5. https://doi.org/10.4103/jos.JOS_135_16.

48. MacKintosh EW, Ho M, White KK, Krengel W 3rd, Bompadre V, Chen ML, et al. Referral indications and prevalence of sleep abnormalities in children with early onset scoliosis. Spine Deform. 2020;8(3):523-30. https://doi.org/1 0.1007/s43390-020-00080-

49. Weiss HR, Goodall D. The treatment of adolescent idiopathic scoliosis (AIS) according to present evidence. A systematic review. Eur J Phys Rehabil Med. 2008:44(2):177-93.

50. Fusco C, Zaina F, Atanasio S, Romano M, Negrini A, Negrini S. Physical exercises in the treatment of adolescent idiopathic scoliosis: an updated systematic review. Physiother Theory Pract. 2011;27(1):80-114. https://doi. org/10.3109/09593985.2010.533342.

51. Zapata KA, Wang-Price SS, Sucato DJ. Six-month follow-up of supervised spinal stabilization exercises for low back pain in adolescent idiopathic scoliosis. Pediatr Phys Ther. 2017;29(1):62-6. https://doi.org/10.1097/pep. 0000000000000325.

52. Thompson JY, Williamson EM, Williams MA, Heine PJ, Lamb SE. Effectiveness of scoliosis-specific exercises for adolescent idiopathic scoliosis compared with other non-surgical interventions: a systematic review and metaanalysis. Physiotherapy. 2019;105(2):214-34. https://doi.org/10.1016/j.physio.2 018.10.004.

\section{Publisher's Note}

Springer Nature remains neutral with regard to jurisdictional claims in published maps and institutional affiliations.

Ready to submit your research? Choose BMC and benefit from:

- fast, convenient online submission

- thorough peer review by experienced researchers in your field

- rapid publication on acceptance

- support for research data, including large and complex data types

- gold Open Access which fosters wider collaboration and increased citations

- maximum visibility for your research: over $100 \mathrm{M}$ website views per year

At BMC, research is always in progress.

Learn more biomedcentral.com/submissions 